\title{
LA CONFLUENCIA INTELECTUAL Y ACADÉMICA EN LA FORMACIÓN ESCOLÁSTICA Y LA OBRA DE INVESTIGACIÓN DE FRANGISCO CURT LANGE
}

\author{
JORGE VELAZCO
}

Una de las figuras más importantes de la investigación musicológica de América Latina es, fuera de toda duda, la de Francisco Curt Lange, sabio cuya solidísima obra lo ha colocado en una cima donde muy escasos han llegado. Su vasta lista de publicaciones y las enormes contribuciones que ha logrado, así como su incesante afán organizador y administrativo permiten parangonarlo incluso con Robert Stevenson (1916), el titán de la musicología latinoamericana. Son de sobra conocidos los aciertos científicos de Lange y tanto en la creación del Instituto Interamericano de Musicología (1938), como en sus estudios acerca de los compositores de Minas Gerais (publicados entre 1946 y 1979), y -en una escala más concreta- su estupendo estudio sobre los últimos días de Louis Moreau Gottschalk (1829-1869) en Río de Janeiro, su obra es uno de los hitos más formidables que en este campo existen.

Pero la vida y obra de Lange han sido estudiados muy detenidamente y tal vez resulte una ocupación relativamente ociosa reseñar o comentar lo que ha sido analizado ya tan a fondo por autores tan importantes como Gilbert Chase (1906), Guillermo Espinosa (1905), Gerard Béhague (1937) y el mismo Stevenson, cuya labor colosal abarca todas las manifestaciones y expresiones del arte musical español y latinoamericano.

Al hablar de valores consagrados, como Lange, con frecuencia se olvida su proceso formativo, lo cual no deja de ser una pequeña laguna, pues a pesar de que la parte trascendente de las actividades de cualquier persona está formada por los resultados y no por el proceso preparatorio del profesional, es indudable que la base de apoyo académico del intelectual contribuye a explicar, en algunos casos, no sólo el alcance de sus realizaciones sino el enfoque y resultado de su obra. Parte de la casi espantosa capacidad de análisis y producción de Stevenson, está basada en el hecho de que entre sus maestros estuvieron Igor Stravinski (1882-1971) y Artur Schnabel (1882-1951).

Es un hecho que tanto los maestros como, en otra medida y proporción, los colaboradores ayudan a definir la dirección intelectual y la capacidad 
analítica y productiva del investigador, por lo cual resulta claro que incluso su elección indica una tendencia y una posibilidad de acción y de pensamiento. En el caso de Lange, es posible afirmar que comentar el proceso académico de su formación musicológica, contribuye a explicar la profundidad de su obra y el alcance de su labor, producto de su gran capacidad y del apoyo que se procuró al principio de su carrera.

Eilenburg, en Sajonia, ciudad natal de Francisco Curt Lange, es una población no muy alejada de Leipzig, uno de los centros intelectuales del mundo europeo y la ciudad sagrada de la música alemana, el sancta sanctorum de Bach (1685-1750) y Mendelssohn (1809-1847). Allí nació Franz Kurt Lange, el 12 de diciembre de 1903. Al tiempo de su nacimiento, nadie imaginó que aquel bebé sería el más brillante musicólogo sudamericano y que antes de cumplir la treintena, sería ciudadano de Uruguay, con su nombre castellanizado al máximo y una vocación panamericana realmente impresionante.

Lange estudió en las universidades de Leipzig, Berlín, Munich y Bonn. Recibió el diploma de arquitecto en 1927 en la Universidad de Baviera y dos años después logró su doctorado en música en el corazón de Renania, luego de haber trabajado con los más grandes músicos y musicólogos europeos de su época. La referencia sobre sus maestros, forma la intención y justificación del presente comentario.

Erich Moritz von Hornbostel (1877-1935) vivió su niñez en uno de los centros sociales que apuntalaban la vida musical de Viena. Su madre, la cantante Helene Magnus, proveyó naturalmente a un medio familiar con una proyección musical extraordinaria. De adolescente, von Hornbostel estudió armonía y contrapunto con Eusebius Mandyczewski (1857-1929), y antes de cumplir los veinte años componía música y era un pianista muy avezado. Mandyczewski, alumno del célebre Eduard Hanslick (1825-1904) y director del archivo de la Sociedad de Amigos de la Música de Viena, también era un buen amigo de Brahms (1833-1897) y editó, entre 1887 y 1897, las obras completas de Schubert (1797-1828), un esfuerzo musicológico que todavía es válido. von Hornbostel estudió ciencias naturales en las universidades de Viena y Heidelberg entre 1895 y 1899 y en 1900 recibió el grado de doctor en química de la Universidad de Viena. Luego de obtener su doctorado, se fue a vivir a Berlín, donde conoció a Carl Stumpf (1848-1936) en la universidad y quedó fascinado con sus investigaciones en los terrenos de la musicología y la psicología práctica. El nombre de Stumpf es uno de los más grandes en el campo de la erudición germánica. Psicólogo, acústico, musicólogo, con fluidez para tocar seis instrumentos musicales y estudios meticulosos de filosofía, teología y ciencias naturales. 
Stumpf era un verdadero tanque pesado del intelecto, un ardiente investigador que fue profesor en la mitad de las universidades europeas importantes de la esfera germánica y que fundó en Berlín el Instituto de Psicología. Sus alumnos más importantes, von Hornbostel y Abraham, fueron los musicólogos cumbre de su momento. El concepto de "psicología del sonido", formulado por él, fue la continuación de las investigaciones de Hermann Helmholtz (1821-1894) en la intersección de la física y la fisiología proyectadas al campo de la psicología pasando el énfasis previamente colocado en el órgano auditivo a la experiencia sensible del sonido y su función. Pese a que sus discípulos, incluyendo a von Hornbostel, plantearon la antítesis de su pensamiento, la obra es de clase suprema y su personalidad es una de las cimas de la musicología.

A partir de 1905, von Hornbostel trabajó como asistente de Stumpf en el Instituto de Psicología. Luego de que el archivo del instituto se volvió el Archivo de Fonogramas de Berlín, en 1906, se convirtió en el director de la institución hasta 1933. En 1917, fue nombrado profesor de la Universidad de Berlín y luego se le otorgó una cátedra sin que tuviera que presentar su tesis de habilitación, requisito que fue suspendido como reconocimiento a sus méritos y labor.

En 1933, fue despedido de sus cargos por los nazis, en vista de que su madre era judía. Con ello, se fue a Suiza y luego viajó a Nueva York, donde obtuvo una cátedra en la Escuela de Investigación Social. En 1934 dejó la enseñanza y se fue a vivir a Cambridge, a causa de su mala salud. Allí pasó los últimos meses de su vida trabajando en un archivo de grabaciones de culturas primitivas para el Laboratorio de Psicología de la universidad.

Von Hornbostel fue socio de Otto Abraham (1872-1926) y, junto con él y Stumpf; se le considera el iniciador del uso del herramental científico de los métodos combinados de la acústica, psicología y fisiología para el estudio de las culturas musicales ajenas a la tradición europea. Abraham, pese a la importancia de su obra y colaboración con von Hornbostel en el campo de la musicología, era médico y su especialidad era la psicología del sonido y la percepción auditiva. La contribución de von Hornbostel fue importantísima para el establecimiento de la musicología comparada, nueva disciplina que recibió su coherencia como resultado del trabajo de estos investigadores.

Junto con Abraham, von Hornbostel publicó una serie de trabajos acerca de la música japonesa, turca, hindú y la de los indios norteamericanos, basada en los materiales del Archivo de Fonogramas de Berlín, y sugirió un sistema para transcribir esa música en la notación occidental, además de su estudio acerca de la psicología del sonido musical. Los puntos 
clave de tal trabajo fueron una serie de estudios que aparecieron entre 1904 y 1926 y cuyo enfoque y metodología puede verse dentro de las bases de la obra de Lange.

Estos dos autores delinearon en 1904 un sistema para trabajar la musicología comparada similar al usado en los estudios linguísticos del mismo tipo. En el Segundo Congreso de la Sociedad Internacional de Música (nombre anterior de la Sociedad Internacional de Musicología), que tuvo lugar en Basilea en 1906, von Hornbostel demostró la manera de usar los datos recabados por la musicología empírica en la investigación etnológica. En 1900, von Hornbostel realizó una investigación de campo entre los indios pawnee para luego concentrarse en incrementar la colección que dirigía. Durante la Primera Guerra Mundial trabajó junto al fisiólogo Max Wertheimer en las bases físicas y fisiológicas de los detectores del sonido, lo cual le dio la posibilidad de grabar música folklórica en los campos de concentración para prisioneros de guerra. Su participación en el Congreso de Música Árabe en El Cairo, en 1932, fue uno de los puntos culminantes de la reunión. Su trabajo Über die Bedeutung ethnologischer Untersuchungen für die Psychologie und Ästhetik der Tonkunst (1910), realizado junto con Stumpf, fue un hito académico similar a otro de sus más célebres sistemas de pensamiento, elaborado con Curt Sachs y uno de los elementos más permanentes de la musicología contemporánea: Systematik der Musik instrumente: ein Versuch (1914). Esta obra nos ha dado la clasificación más usual de los instrumentos musicales, de uso general y aceptación internacional. Los discípulos de von Hornbostel, además del propio Lange, forman una verdadera pléyade musicológica que dio a su escuela y pensamiento una influencia muy notable. Los más prominentes son: Marius Schneider (1903), quien también estudió el piano con Alfred Cortot (1877-1962), etnomusicólogo y experto en el campo hornbosteliano de la musicología comparada, creador de la escuela de Colonia que sucedió a la escuela de Berlín de von Hornbostel. El etnomusicólogo George Herzog (1901), de amplio reconocimiento académico en el mundo entero. Fritz Bose (19061975), notable tratadista de fonética musical, etnomusicología y canción folklórica. Walter Wiora (1907), musicólogo en el más amplio y general sentido, quien enfocó la evolución histórica, y el etnomusicólogo Mieczyslaw Kolinski (1901), autor de obras para carrillón, instrumento que dominó profundamente, como autor y como intérprete, refugiado en América en 1938 a causa de la hostilidad nazi en contra de los judíos y uno de los musicólogos clave de la época. Heinrich Husmann (1908), historiador y musicólogo que ha cultivado el estudio de la música del oriente y la antigüedad mediante la herramienta de la musicología comparada sobre la 
tradición europea, experto como pocos en el tropo y la secuencia. Robert Lachmann (1892-1939), experto en música semita y cantos orientales, que abarcó brillantemente la música árabe en sus manifestaciones propias de Túnez, Egipto, Marruecos e Iraq. Vivió un tiempo en El Cairo, como experto del gobierno egipcio, y terminó sus días en Jerusalén, refugiado de la ola nazi que amenazó a todo judío y destruyó a muchos de ellos. Otro de los más poderosos alumnos de von Hornbostel fue Hans Robert Hickmann (19081968), preocupado principalmente por la música egipcia y sus conexiones con la música occidental, también consejero del gobierno egipcio y residente de El Cairo durante algún tiempo en el ejercicio de su especialidad.

Pese a la visión y amplitud de los trabajos de von Hornbostel, que son una lista de 139 publicaciones de obras de investigación, el erudito nunca publicó una síntesis de su pensamiento, pero tanto su clasificación de instrumentos como sus estudios acerca de la psicología de la percepción musical y las implicaciones interculturales de los sistemas de afinación son de importancia permanente en la musicología y han sido usados insistentemente por Lange.

Cuando Lange vivía y estudiaba en Munich, conoció a un hombre de gran trascendencia en su vida intelectual y personal, Karl Vossler, quien fue su profesor de filología romance. Vossler debe de haber sido un individuo muy particular, de esos grandes pedagogos cuya sabiduría está enlazada con una bondad humanista de carácter fundamental, los cuales dejan huellas permanentes en los afortunados alumnos que tienen el privilegio de tratarlos. Lange lo describe, en una carta, como una "....personalidad por mí idolatrada, a quien debo... mi acendrada tendencia a la humanística musicológica, particularmente en lo que se refiere a mi formación hispánica" "Creo que todo estudiante ha tenido la fortuna de conocer al menos a un maestro de esa clase, a veces con una proyección profesional de gran fama, en ocasiones sin mayor celebridad general, pero con una calidad intelectual y humana de altísimo nivel, que consigue formar verdaderamente las almas confiadas a su cuidado. El Dr. Karl Vossler no tuvo el relieve general de los otros profesores de Lange, pero -según la descripción proveniente de los recuerdos del propio Lange- fue un punto capital de su ciclo escolar, ya que, como dice Lange, "él tuvo en mi vida de joven ávido por saber una considerable influencia y fue él quien me sugirió el camino hacia América Latina en momentos de profunda crisis". Esto es, sin duda, suficiente para incluir en este texto a Vossler, a pesar de que el calibre general de su obra no tenga el diámetro ni el peso en la musicología de las eminentes figuras cuya labor pedagógica contribuyó a la formación escolástica de Lange. 
Aquí hay que mencionar también al 'ínico maestro de Lange que no representa un elemento académico sist mático ni ortodoxo. Karl Montgomery Rufus Siegfried Straube (1873-19:0) obtuvo su máxima formación en el seno familiar, principalmente de su padre, quien era organista y organero. Su estrato superior se lo dio la experiencia práctica en el riquísimo ambiente musical, artístico e intelectual de Berlín, donde fue nombrado suplente del órgano de la Kaiser-Wilhelm-Gedächtnis-Kirche en 1895. Afiliado a la escuela de Hans von Bülow (1830-1894) en su enfoque artístico, se fue a Wesel en 1897, esta vez en calidad de organista titular y principió su amistad con Max Reger (1873-1916), que fue muy estrecha. En 1902 recibió el nombramiento de organista de la iglesia de Santo Tomás de Leipzig y en 1918 ascendió al cargo de Kantor de la iglesia, que fue ocupado en el siglo XviII por Johann Sebastian Bach (1685-1750). Su evolución estilística natural, lo llevó de los conceptos de von Bülow al sistema de ricas texturas de Liszt (1811-1886) y el pesado movimiento cromático característico de la noción armónica de Wagner (1813-1883). Sin embargo, su experiencia práctica en Leipzig lo condujo poco a poco a una posición de rigor muy ortodoxo, en el que las particularidades del sonido básico de Hieronymus Praetorius (1560-1629) y su familia, tanto como la idea sonora de la familia Schnitger $(c .1620-c .1740)$ se reflejaron de manera sintética en la gran definición sonora del órgano de los Silbermann (16781783). Sus ejecuciones de motetes de Bach, de frecuencia semanal, enfatizaron muchísimo el rigor académico en la interpretación de la música del gran creador. En los seis festivales Bach que organizó entre 1904 y 1923, y en su intensa vida como director de coros, tal vez el más famoso en el canto bachiano de la época en Alemania, su actitud musical y estética se alineó con el más estricto celo musicológico acerca del respeto y la supervivencia de las tradiciones barrocas, tal y como se les puede recordar en el siglo $\mathrm{XX}$. $\mathrm{Su}$ contribución en este campo ha sido definitiva para reconstruir la estructura de la música de Bach según se le acepta hoy en día en los círculos musicológicos más severos. El trato pedagógico de Lange con Straube y Nikisch ha sido la única zona de la interpretación musical trascendente que fue cultivada por el destacado musicólogo.

De los maestros de Lange, el de mayor interés artístico fue Artur Nikisch (1855-1922), de quien hay una bella opinión emitida por Chaikovski (18401893), en el año de 1887:

El señor Nikisch tiene una elegante calma y se ahorra todo movimiento superfluo, si bien, a la vez, tiene una fuerza maravillosa y un control completo. No parece dirigir, sino más bien ejercer una especie de conjuro misterioso; apenas 
hace alguna seña visible y nunca intenta llamar la atención sobre sí mismo; sin embargo, sentimos que la gran orquesta, como un instrumento en las manos de un maestro incomparable, está completamente bajo el control de su director:

Toda una generación de directores recibió una fuerte influencia de él, incluyendo a Wilhelm Furtwängler (1886-1954), su sucesor en Leipzig y Berlín, y Sir Adrian Boult (1889-1983).

Nikisch fue un músico afortunado que, luego de cursar estudios de violín con Joseph Hellmesberger (1855-1907) y de composición con Otto Dessoff (1835-1892), tocó la Novena Sinfonia de Beethoven bajo la dirección de Wagner (1813-1883) y después tocó dirigido por Brahms, Liszt (18111866) y Verdi (1810-1901). Participó en el estreno de la Segunda Sinfonía de Bruckner bajo la dirección del compositor y dirigió el estreno de la Séptima Sinfonia del mismo autor en 1884. En 1895 fue nombrado director de la Orquesta del Gewandhaus de Leipzig, como sucesor de Carl Reinecke (1824-1910) y de la Orquesta Filarmónica de Berlín, como sucesor de Hans von Bülow. Para entonces ya había sido director de la Orquesta Sinfónica de Boston (1889) y de la Ópera de Budapest (1893). Su interpretación de la Quinta Sinfonia de Chaikovski le dio a la obra la fama que todavía disfruta y su apoyo de Mahler (1860-1911), Reger y Strauss fue un factor decisivo en el lugar profesional que estos autores tienen en la historia. Su propia obra de compositor está olvidada, pero su hijo, Mitja Nikisch (1899-1936), tuvo una exitosa carrera como pianista. Nikisch fue uno de los más grandes directores de la historia y uno de los más admirados artistas de Europa.

Otro de los maestros de Lange fue Adolf Sandberger (1864-1943), quien además de ser musicólogo, dedicó una gran parte de su esfuerzo vital a la composición musical, pese a que sus frutos científicos fueron más notables que los artísticos. Sandberger estudió composición en Würzburg y en Munich entre 1881 y 1887, y trabajó la musicología en Munich y en Berlín entre 1883 y 1887. Entre sus maestros estuvieron Joseph Rheinberger (1839-1901) y nadie menos que Julius August Philipp Spitta (1841-1894), uno de los reyes de la musicología germánica y uno de los grandes exponentes de la erudición alemana, quien hablaba, leía y traducía con máxima fluidez el latín y el griego clásicos, amigo personal de Brahms, postulador de una teoría crítica historicista basada en la filosofía kantiana, quien logró su altura máxima con su por todos conceptos formidable investigación sobre Bach, cuya expresión bibliográfica vio la luz en 1873.

Sandberger recibió su doctorado en la Universidad de Würzburg en 1887 con una tesis acerca de Peter Cornelius (1824-1874) y luego realizó diversos viajes de estudio por Italia, Francia, Rusia y Austria. En 1889 
alcanzó el cargo de curador del departamento de música de la Biblioteca Estatal de Baviera. Luego de completar su disertación magistral con un trabajo acerca de Orlando di Lasso (1532-1594), obtuvo la cátedra de musicología de la Universidad de Munich en 1900 y fue nombrado profesor de tiempo completo en 1904. Fue el primero en ocupar estos puestos en lo que era sólo una nueva disciplina independiente en esa época. Antes de su jubilación, en 1930, la enorme fama que logró como un académico de gran relieve y un experto en los nuevos métodos de investigación musical, le ayudó a fundar una escuela de musicología en Munich y ejercer una influencia determinante por medio de su obra y sus discípulos, gente como Ernst Bücken y Alfred Einstein (1880-1952), primo de Albert Einstein (1880-1952) y musicólogo de amplios vuelos y gran multiplicidad de campos. Además, hay que mencionar a Theodor Kroyer (1873-1945), el gran experto en el madrigal italiano, quien también fue alumno de Rheinberger. Vale la pena enfatizar la gran raíz musicológica en esta zona de los antecedentes académicos de Lange. El sofisticado enfoque de Kroyer en sus estudios acerca del cromatismo en el madrigal italiano, su obra sobre el motete y su trabajo investigador en el campo de Ludwig Senfl (c..1486-1543?) son la contrapartida de sus dos magníficos libros que tratan a dos de sus maestros principales, Rheinberger y Walter Courvoisier (1875-1931), obras que son los tratados definitivos en ambos temas. Kroyer tuvo una distinción académica de un peso enorme, ya que fue el sucesor de Hermann Albert (1871-1927) en la Universidad de Leipzig en 1923. La obra de Albert como investigador de la música griega clásica y el fundamento estético de la melodía medieval es trascendente. Él fue el primer musicólogo admitido en la Academia Prusiana de Ciencias de Berlín y su rico enfoque humanista de la investigación musicológica le permitió escribir su estupenda biografía de Mozart (1756-1791), todavía uno de los hitos del tema pese a la extensión y profundidad de la moderna obra de investigación acerca del mismo. Sus labores en los campos de Beethoven (17701827), Schumann (1810-1856), Meyerbeer (1791-1864) y el romanticismo son pilares en sus respectivas áreas. A su vez, Albert fue sucesor de Riemann en Leipzig y de Kretzschmar en Berlín, por lo que su importancia intelectual fue sólo una faceta de su enorme prestigio profesional. Joseph Gabriel Rheinberger, el otro maestro de Sandberger y antepasado académico de Lange, tuvo importancia como compositor, organista y director de orquesta, pero fue su actividad pedagógica la que le dio una tremenda influencia en el pensamiento musical del entresiglo XIX-XX, ya que sus principales alumnos, además del propio Sandberger, fueron: Engelbert Humperdinck (1854-1921), Ermanno Wolf-Ferrari (1876-1948), Ludwig 
Thuille (1862-1907), el pedagogo norteamericano Horatio Parker (18631919), Theodor Kroyer y Wilhelm Furtwängler.

Paul Mies (1889-1976), otro de los maestros célebres de Lange, tuvo un espectro intelectual de gran amplitud y estudió matemáticas y física en la Universidad de Bonn mientras recibía entrenamiento en musicología bajo la dirección de Leonhard Wolff(1848-1918). En 1912, recibió su doctorado en la Universidad de Bonn con una tesis acerca de la pintura tonal en la música. Su profundo enfoque y su metodología ortodoxa por excelencia, se concentraron en una expresión de resultado muy singular, que lo llevó a un sistema para describir el proceso de composición y su relación con la determinación del efecto musical de la obra creadora. Temas tan sutiles como el estilo de ejecución pianística de Beethoven y su proyección en la cultura pianística de su época, son características de la manera como Mies enfocó la musicología. También hay que recordar su trabajo para poner en concordancia el estilo eclesiástico de Bach y la recepción auditiva del público moderno.

Sus estudios históricos acerca de la música en Colonia son modelo proverbial de capacidad y cuidado y su investigación acerca de Beethoven, Schubert (1797-1828) y Brahms le dio una fama y un reconocimiento que culminaron en su nombramiento como miembro del consejo directivo de la Beethovenhaus de Bonn en 1946. En ese mismo año ingresó al claustro académico del Institut für Schulmusik de la Escuela Superior de Música de Colonia. Es indudable que la especial virtud del trabajo de Mies en el campo del análisis y el estudio estilístico se proyectó con gran fuerza en su enseñanza y que algunos rasgos académicos de Lange pueden ser trazados hasta este sólido y competente origen.

Otro importante discípulo de Sandberger fue Erich Schenk (1902-1974), experto en la música del barroco y el clásico, el primer musicólogo que ocupó el cargo de rector de la Universidad de Viena. Karel Philippus Bernet-Kempers (1897-1974) fue uno de los más distinguidos especialistas en Mozart y Schubert, que como experto en motetes logró reconocimiento europeo con su tesis doctoral sobre Clemens non Papa. También alumno de Sandberger, Ludwig Schiedermair (1876-1957) alcanzó un lugar prominente como investigador de la música de Mozart y Beethoven. Por último, debemos mencionar al infortunado Kurt Huber (1893-1943), antagonista de los nazis y ejecutado por ellos, cuya importante obra en los campos de la etnomusicología y la estética se conserva en parte con base en sus apuntes como estudiante, en virtud de las tristes circunstancias de su vida después de 1933.

El campo primario del interés de Sandberger fueron los clásicos vieneses 
y la música del siglo Xvi. Sus escritos acerca de di Lasso han sido un pilar de la investigación en esa rama. Otros trabajos de vanguardia escritos por Sandberger son: Zur älteren italienischen Klaviermusik (1918), Zu den unbekannten Sinfonien von Josef Haydn (1937) y Zur venezianischen Oper (19241925).

Sandberger compuso dos óperas, canciones, coros y algo de música de cámara. Como compositor, trató conscientemente de asimilar los estilos de Peter Cornelius (1824-1847), Max Reger (1873-1916) y Richard Strauss (1864-1949), pero el resultado final es, digamos, un tanto académico. La enjundia no va bien con la intuición requerida por la creación artística de altos vuelos; hasta el momento no se ha visto el polo ideal que intersecte las dos formas de pensamiento. En el caso de Sandberger, puede medirse aquel primer elemento por su labor, la influencia de su escuela y el hecho de que fue invitado como miembro de numerosas sociedades dentro y fuera de Alemania. La proyección artística se ha medido en la total oscuridad y desconocimiento de su obra creativa, reflejo de su intelectualmente mediatizada intuición.

Uno de los más famosos discípulos de Sandberger, también maestro de Lange, fue Ernst Bücken (1884-1949), quien principió su carrera intelectual en Bonn, como jurista. Sus estudios de derecho desembocaron en un ciclo académico de musicología, estudios de cultura germánica y filosofía en la Universidad de Munich, que coexistieron con sus clases de composición con Walter Courvoisier y piano con Walter Braunfels (1882-1954). Walter Courvoisier fue un médico que se volvió músico en 1902 y quien estudió musicología con Sandberger y composición con el amigo, discípulo y colega de Richard Strauss, Ludwig Thuille. Braunfels, cuya interesante obra de compositor se niega a desaparecer, había sido discípulo del célebre Theodor Leschetizky (1830-1915). Además de Sandberger, la educación musicológica de Bücken tuvo como base a Kroyer. Una tesis acerca de la vida y obra de Anton Reicha (1770-1836) le dio su doctorado en 1912 y en 1920 obtuvo la cátedra en la Universidad de Colonia con un trabajo sobre el estilo heroico en la ópera. Además, fue profesor de la Technische Hochschule de Aquisgrán y de la Hochschule für Musik de Colonia. Cuatro importantes sociedades académicas europeas lo hicieron miembro: la Academia Germana (1933), la Vereeniging voor Nederlandse Muziekgeschiedenis (1936), el Instituto Estatal para la Investigación Musical (1942) y la Sociedad Antonio Vivaldi de Venecia (1947).

La obra de Bücken tiene una peculiar característica: liga la seriedad del investigador con la delicadeza sensible del artista; su credo vital fue la utilización de la musicología como medio para reconocer y exaltar los 
valores y relaciones artísticas. En ese campo, su enfoque se aparta por completo del sistema germánico tradicional para ejercer la musicología, representado por obras como la de von Hornbostel, Sachs o Hugo Riemann (1849-1919), uno de los más grandes santones de la musicología germánica, alumno del ya legendario Salomon Jadassohn (1831-1902). Riemann escribió cincuenta y ocho libros, la mayoría muy importantes, y más de doscientos ensayos y artículos largos, todos sesudos, admirablemente logrados. En 1882 apareció su Musik-Lexikon, obra que por sí sola justifica una vida pero que no es sino una de las tantas producciones importantes de este titán de la musicología.

Bücken manejó un panorama muy amplio de trabajo, que integró a través de un enfoque sobre los estilos musicales y los estudios biográficos, el cual usó para fortalecer y animar la investigación basando los estudios estilísticos en el trabajo académico. Algunas de sus publicaciones muestran claramente su enfoque y su vasto campo de interés en diversas áreas especializadas y en las múltiples fases del desarrollo de la música en la historia.

Este interesantísimo musicólogo intentó integrar la estética musical con la historia de la música para desarrollar un concepto histórico del estilo y su enfoque produjo investigación original. En la muy importante serie Handbuch der Musikwissenschaft, que publicó en diez volúmenes a partir de 1927, aparecieron tópicos como el representado por Die Musik des Mittelalters und der Renaissance de Heinrich Besseler (1900-1969), cuyo estudio monumental de la música del siglo XV, Der Musik des Mittelalters und der Renaissance (1931) alcanzó fama imperecedera. También se publicó Die Aufführungspraxis der Musik de Robert Haas (1886-1960), director de ópera y gran especialista en el barroco, el clásico, Mozart y Bruckner (1824-1896). Esta clase de temas se presentaron por primera vez en un marco académico y musicológico en la obra editada por Bücken. La importante serie de ediciones que Bücken impulsó y coordinó a partir de 1932, Die grossen Meister der Musik, ha tenido secuelas hasta este año, con inclusión de la misma repercusión del nombre en diversas series de divulgación musical en todo el mundo.

Lange fue también discípulo de uno de los más importantes musicólogos de Alemania en el área del estudio de Mozart, Beethoven y la interrelación entre la fuerza política del mecenazgo artístico y su efecto en el medio musical de una época. Ludwig Schiedermair (1876-1957) fue uno de los más distinguidos alumnos de Sandberger mientras completaba su ciclo intelectual estudiando historia y literatura alemanas en la Universidad de Munich. Su tesis doctoral (1901) acerca de la vida cultural en la corte del príncipe Fernando María, elector de Baviera, alcanzó una gran resonancia, 
pese a que jamás fue publicada. Durante algún tiempo, Schiedermair dejó la musicología en favor de la enseñanza de la historia, la geografía y el alemán, pero en 1905 volvió a su pasión intelectual favorita en el mejor nivel posible, como alumno de Riemann y Kretzschmar. Luego de realizar extensos y profundos viajes por Italia, se colocó en la plaza de disertador en historia de la música en la Universidad de Marburgo en 1906. En 1911 se fue a Bonn, donde alcanzó una cátedra titular en 1920, que conservó hasta su jubilación en 1945 .

Schiedermair fue otro de los grandes expertos en la vida y obra de Beethoven y su interés y esfuerzo lograron que los trascendentes Archivos Beethoven fueran sistematizados y organizados con el pretexto del centenario del fallecimiento del compositor. Este importante centro de investigación, fundado y dirigido por Schiedermair, logró acumular en una sola colección no únicamente los manuscritos (en original o en fotografía) de Beethoven, sino que consiguió extender su obra de catalogación y clasificación hasta muchos de los bosquejos y los manuscritos que se hallaban desperdigados por todo el mundo. En 1929, Schiedermair fundó un departamento dedicado a investigar la historia de la música renana, el cual se amplió en 1933 con una sección de publicaciones, que ahora forma parte de la Facultad de Música de la Universidad de Colonia. La obra bibliográfica e histórica de Schiedermair le trajo los usuales honores y resultó presidente de la Sociedad Alemana de Musicología en 1937 y presidente de la sección de música de la Academia Alemana en 1940.

La importante obra de Schiedermair se concentró en Mozart y Beethoven. Principió con la publicación de cuatro volúmenes de cartas de Mozart y terminó con su interesante trabajo acerca de la música renana de 1947, pasando por su notable investigación sobre la juventud de Beethoven realizado en 1925. Las cualidades de Schiedermair como bibliógrafo, investigador, maestro y organizador parecen reflejarse en la forma como Lange ha realizado su propia esfera intelectual y académica.

Otro de los maestros cuya presencia intelectual e influencia académica fue natural en el caso de Lange, a causa del tema de su tesis doctoral (Über die Mehrstimmigkeit der Niederländischen Motetten, Bonn, 1929), fue el muy eminente $y$ enjundioso investigador belga Charles Jean Eugène van den Borren (1874-1966), quien principió su ciclo académico en calidad de jurista de la Universidad de Bruselas en 1897, pero que abandonó en 1905 su carrera como abogado del Tribunal de Apelación para dedicarse a los estudios musicales mediante la inscripción en la cátedra de historia de la música de Maurice Kufferath (1852-1919) y estudios de armonía, contrapunto y fuga con Ernest Closson (1870-1950). Kufferath fue cellista, direc- 
DOI: http://dx.doi.org/10.22201/iie.18703062e.1992.63.1639

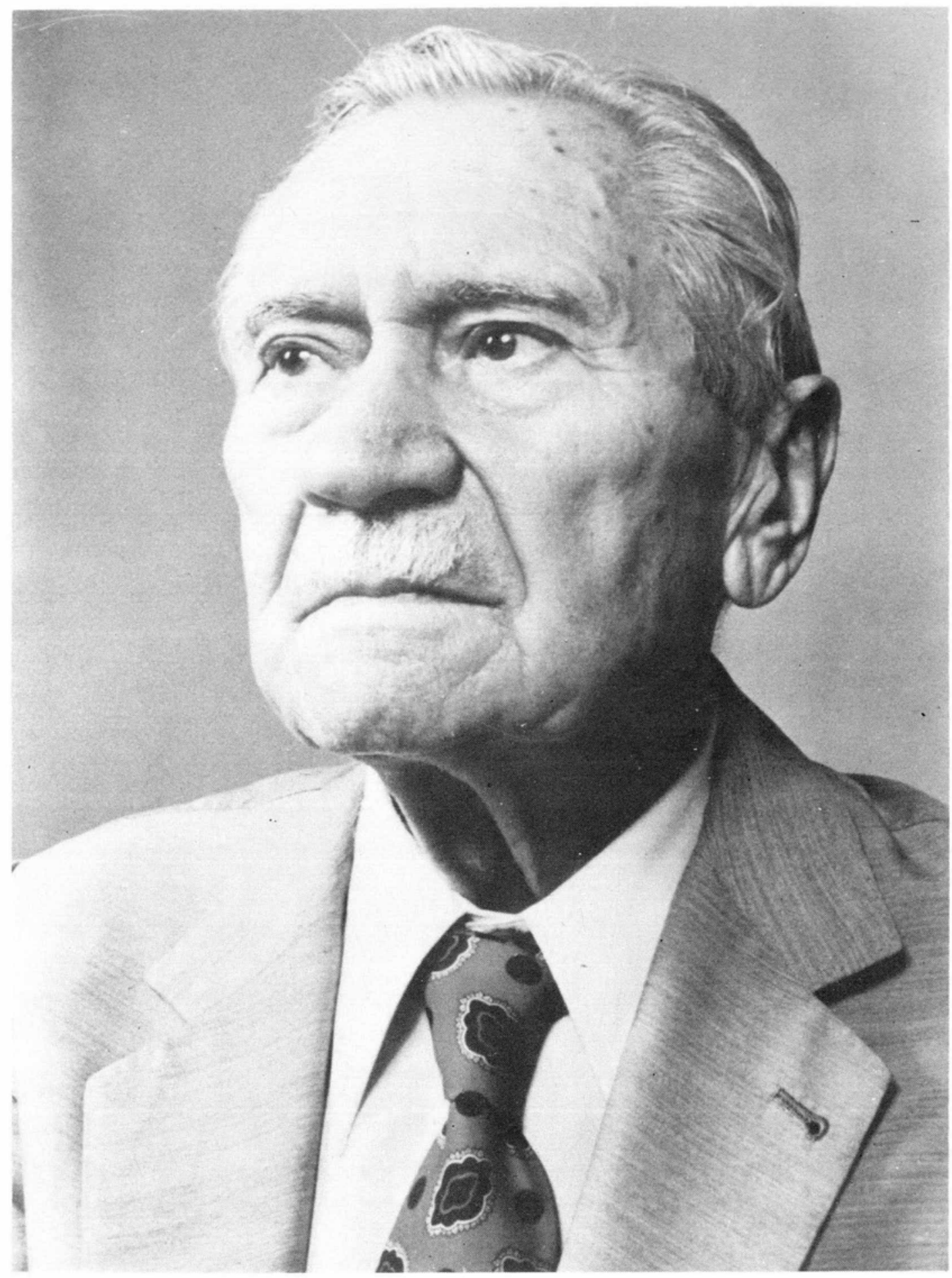

1. Francisco Curt Lange. 
tor de orquesta, escritor de tendencia fervientemente wagneriana y director del Teatro de la Moneda de Bruselas de 1900 a 1914. Durante su gestión tuvieron lugar los estrenos mundiales de Le Roi Arthus de Ernest Chausson (1855-1899) y Pepita Jiménez de Albéniz (1860-1909). Closson se hizo famoso principalmente por sus estudios acerca de las raíces flamencas de Beethoven, en los que demostró su capacidad para apoyar la intuición con la sistematización de los hechos y cuyos resultados publicó en 1928, en su famoso libro L'élément flammand dans Beethoven. Entre 1909 y 1914 trabajó como crítico musical del periódico L'indépendance belge y también colaboró con otras publicaciones mientras que daba clases en el Instituto de Altos Estudios Musicales y Dramáticos de Bruselas acerca de los orígenes de la polifonía y la historia de la música en los Países Bajos, campo de especialidad que fue su fuerte principal. Disertó también en esa época sobre la historia de la música para teclado en la Universidad Libre de Bruselas.

En 1919, van den Borren fue nombrado bibliotecario del Real Conservatorio de Bruselas, como sucesor de Alfred Camille Wotquenne-Platel (1867-1939), alumno del famoso François-Auguste Gevaert(1828-1908) y el gran bibliotecario belga de su época, responsable de una gran cantidad de muy valiosas adquisiciones y sistematizador de altos vuelos de aquel formidable acervo bibliográfico. En ese puesto permaneció hasta su jubilación en 1940. Durante su encargo la biblioteca realizó importantes adquisiciones, como el fondo Ste. Gudula, formado por cientos de manuscritos del siglo XVIII provenientes de una de las principales iglesias de Bruselas.

Van den Borren fue catedrático de historia de la música de la Universidad Libre de Bruselas de 1926 a 1945 y también fue profesor de musicología de la Universidad de Lieja de 1927 a 1944. Como miembro activo de la Sociedad Internacional de Musicología, fue uno de los más influyentes componentes de su consejo directivo de 1927 a 1954. En 1939, fue electo miembro de la sección de bellas artes de la Academia Real de Bélgica y fungió como presidente en 1953. Cuando se formó la Sociedad Belga de Musicología, en 1946, van den Borren fue el primer presidente de la institución. Tal vez su más conocida contribución ha sido la integración del grupo interpretativo Pro Musica Antiqua, que fundó en 1933 junto con su yerno, el compositor y director Safford Cape (1909-1973), con el objeto de tocar, de la manera más fiel y seria posible, el repertorio comprendido entre 1200 y 1600 . Van den Borren fue el asesor musicológico del grupo y los aciertos de ambos fueron muy notables.

Este musicólogo tuvo gran influencia y distinción como historiador y crítico. Su investigación se concentró en la música flamenca, tema que tomó en su más amplio espectro geográfico y temporal, con lo que cubrió 
no sólo a Holanda sino también a Bélgica, desde la Edad Media hasta la época moderna. Tuvo un especial interés en la música británica de la alta Edad Media y el Renacimiento y su interacción con la música contemporánea de los Países Bajos. Escribió cientos de artículos, capítulos enteros y voces de importantes diccionarios y enciclopedias. Su obra sobre los orígenes del vastísimo desarrollo de la polifonía vocal en el siglo Xvi y la primitiva música para teclado en Inglaterra y los Países Bajos siguen siendo una muy autorizada fuente de conocimiento.

La influencia de la escuela de van den Borren tuvo extensión internacional ya que, al margen de sus actividades académicas fuera de Bélgica, fue maestro de muchos intelectuales. Además de Lange, entre sus discípulos hubo nombres tan eminentes como el de Thurston Dart (1921-1971). Sus sucesores en sus cátedras de Lieja (Suzanne Clerex-Lejeune, 1910) y Bruselas (Robert Wangermée, 1920) son musicólogos notables. Wangermée logró incorporar en una sola carrera las actividades académicas y administrativas. Fundó el Centro de Sociología de la Música de la Universidad Libre de Bruselas en 1964 y ha hecho toda una carrera en la radio-televisión belga que lo llevó desde un origen técnico al puesto de director musical en 1953 y luego al cargo de director general de transmisiones en lengua francesa en 1960. También lo fue Albert van der Linden (1913-1977), uno de los más distinguidos discípulos de van den Borren y su sucesor como bibliotecario del Real Conservatorio de Bruselas. La obra pedagógica de van den Borren permitió a la musicología histórica de Bélgica su colocación como disciplina universitaria, que el gran investigador basó en la magna obra de François-Joseph Fétis (1784-1871), van der Straeten (1826-1895) y Gevaert (1828-1908), a cuya contribución en el enfoque histórico él añadió el sistema y el método de la musicología moderna, en parte creados por el mismo destacado académico.

En 1945, veinte profesores belgas publicaron un volumen para celebrar el septuagésimo aniversario de van den Borren. La lista de publicaciones del maestro hasta esa fecha incluía cerca de cuatrocientos títulos. Cuando se celebró su nonagésimo aniversario, la lista de publicaciones de van den Borren -quien siguió activo hasta el final de su vida- se llevó treinta páginas de tipo fino. Sus escritos y su enseñanza le permitieron lograr una extraordinaria combinación de objetividad en el análisis y subjețividad letrada en el juicio estético. Sus estudios no sólo hablan de la forma y estructura de la música, sino que también presentan en lo posible la personalidad de los compositores, con la ubicación que tuvieron en el contexto histórico y social de su época.

Curt Sachs (1881-1959), uno de los más importantes maestros de Lange, 
fue un gigante de la musicología, un practicante inconsciente del fair play imperial británico y un consciente sacerdote de la Gründlichkeit de su sociedad natal. Sachs estudió en el Gymnasium Francés de Berlín y a la vez tomó clases de piano, teoría musical y composición. Después se doctoró en historia del arte en la Universidad de Berlín con una tesis acerca de la escultura de Verrocchio (1904), pese a que también atendió los cursos de musicólogos muy importantes: Kretzschmar, Oskar Fleischer (1856-1933) y Johannes Wolf (1869-1947). August Ferdinand Hermann Kretzschmar (1848-1924) tuvo una especial importancia como musicólogo. Fue también director de orquesta y recibió su doctorado con una tesis de altos vuelos escrita en latín en 1871. Alumno de Carl Reinecke, fue sucesor de Joseph Joachim (1831-1907) en la Hochschule de Berlín, que dirigió de 1909 a 1920. Además, fundó en 1890 la Sociedad Bach de Leipzig, que sigue viva y activa hasta nuestros días. Fleischer había sido alumno de Spitta y se le ha tachado de fantasioso y fanático a causa de su sistema para la transcripción de melodías gregorianas, que es muy innovador pero que no logró reconocimiento. La intuición sólo se acepta en el aséptico mundo de la musicología cuando se prueba con las armas y herramientas musicológicas adecuadas y dentro del sistema intelectual propio de la disciplina. Tal vez esta herencia intelectual le dio a Sachs esa extraña posición con la que anduvo descifrando la música caldea, babilonia y asiria. Wolf fue alumno de Riemann y también director de la colección de música de la Biblioteca del Estado Prusiano. Era un paleógrafo impresionante y su labor como investigador en las fuentes directas fue una de las bases del estudio y el desarrollo de la musicología sobre la época medieval y renacentista. Entre 1908 y 1921, salió su gran edición de las obras completas de Jakob Obrecht (c. 1450-1505).

Sachs intentó primero hacer carrera como historiador de las artes plásticas, pero a partir de 1909 principió a dedicarse por completo a la musicología. En 1919, luego de su servicio militar en la Primera Guerra Mundial, se le nombró director de la Colección Estatal de Instrumentos Musicales, la cual reorganizó y restauró consiguiendo que algunas piezas de museo volvieran a ser instrumentos vivos para la ejecución musical. En 1921 daba clases en la universidad y en 1928 logró una cátedra titular; también era profesor en la Escuela Estatal de Altos Estudios Musicales y en la Academia de Música Sacra. Alcanzó rápidamente su fama y ya para 1930 el gobierno egipcio lo invitó como consultor de música oriental.

En 1933, Sachs fue privado de toda posición académica, ya que era judío. Emigró a París y trabajó allí en el Museo del Trocadéro (hoy Museo del Hombre) bajo la dirección de André Schaeffner (1895), etnomusicólogo 
alumno de Vincent d'Indy (1851-1931), quien sintetizó sus estudios de etnología, música y arqueología para fundar el departamento respectivo en el museo, el cual dirigió de 1929 a 1965 . También fue el secretario artístico de la Orquesta Sinfónica de París de 1929 a 1931 y catalogó la Biblioteca del conservatorio entre 1932 y 1941.

Sachs completó su vida parisina dando clases en La Sorbona y realizando su importante serie de grabaciones L'Antologie Sonore. En 1937, emigró a los Estados Unidos y trabajó en la Universidad de Nueva York, en la Biblioteca Pública de Nueva York y en la Universidad de Columbia. Fue presidente de la Sociedad Americana de Musicología de 1950 a 1952 y presidente honorario de la Sociedad Americana de Etnomusicología.

La obra de Sachs se caracteriza por una capacidad especial para compendiar una visión sintética de panoramas muy vastos. Ello le permitió abarcar grandes campos y realizar una labor pedagógica y divulgatoria muy grande, en el más alto nivel académico. Fue de los fundadores de la organología moderna y, junto con von Hornbostel, diseñó el esquema de clasificación instrumental más ampliamente aceptado. A través de los instrumentos, se interesó en la música de las culturas ajenas a la europea y fue uno de los pioneros de la etnomusicología. Realizó una obra inmensa y ejerció, mediante sus publicaciones y su cátedra, una influencia trascendental en la musicología.

Georg Schünemann (1884-1945) ocupó un lugar especial en la formación de Lange. Como todo erudito, Schünemann estudió diversas áreas del conocimiento: literatura alemana y filosofía en la universidad de Berlín y musicología con Kretzschmar, Wolf, Fleischer, Stumpf y Friedländer. Max Friedländer (1852-1934) fue alumno del barítono Manuel García (18051906) en Londres y también trabajó bajo la dirección de Spitta. Los campos más fuertes de su investigación fueron el lied y la canción folklórica alemana. En 1907, Schünemann se doctoró con una tesis acerca de la historia de la dirección de orquesta, tema al que llegó en parte gracias a su trabajo como flautista en una orquesta sinfónica. En la Primera Guerra Mundial tuvo la posibilidad de realizar investigación práctica, un tanto amarga, en campos de concentración de los prisioneros rusos, donde grabó una colección de canciones de los colonizadores alemanes de Rusia. A partir de 1919 dio clases en la Universidad de Berlín y en 1920 fue nombrado director adjunto de la Hochschule für Musik de Berlín, sucediendo a Franz Schreker (1878-1934) como director en 1932. Con el advenimiento del régimen nazi, al año siguiente, fue súbitamente despedido de todos sus cargos, pero poco después se le nombró director de la Colección Estatal de Instrumentos Musicales y en 1935 recibió el encargo 
de director de la sección de música de la Biblioteca del Estado Prusiano.

Schüneman fue uno de los fundadores del sistema moderno de educación musical en Alemania. Se dedicó muy afanosamente a resolver los problemas pedagógicos de la educación musical elemental y abrió una clase práctica en la sección de pedagogía de la Hochscule für Musik de Berlín, así como clases avanzadas de dirección coral y un curso de práctica orquestal. En 1930, Schünemann y Leo Kestenberg estaban reorganizando todos los aspectos de la educación musical pública y privada en Prusia. Leo Kestenberg (1882-1962) había sido alumno de piano de Franz Kullak (1844-1913) y del formidable genio de Ferruccio Busoni (1866-1924) en el mismo instrumento, pero por ser judío, tuvo que abandonar Alemania y privar a su país de su experta colaboración en materia educativa. En 1938 emigró a Tel-Aviv y allí trabajó como gerente de la Orquesta Filarmónica de Israel y aplicó su talento a la educación musical del país.

Gracias al trabajo de Schünemann, la escuela que dirigió se convirtió en una de las más importantes instituciones académicas de Alemania y del mundo y sus niveles de excelencia siguen siendo un parangón en la rama. A pesar de la bondad del trabajo musicológico de Schünemann y de que sus traducciones al alemán de Don Giovanni, Cosi fan tutte y Las bodas de Figaro de Mozart se siguen usando en Alemania, es gracias a su labor pedagógica como pasó a la historia y la mayor parte de su obra se refiere a la educación musical y temas conexos.

El último de los maestros musicólogos de Lange que mencionaremos es Max Seiffert (1868-1948), quien fue, a su vez, alumno de Spitta y quien se doctoró en la Universidad de Berlín en 1891, con una tesis acerca de J P. Sweelinck (1562-1621) y sus discípulos alemanes. Durante largo tiempo se dedicó a la enseñanza privada y a dar clases en la Hochschule für Musik y en la Academia de Música Sacra de Berlín. En 1935, cuando se creó el Instituto Estatal para la Investigación de la Música Alemana, Seiffert fue nombrado director y desempeñó el cargo hasta 1942. En 1912, había sido nombrado senador de la Academia de Artes y en 1928 la Universidad de Kiel lo invistió como doctor honoris causa. Seiffert fue el supervisor, como secretario permanente de la comisión editorial, de la formidable colección Denkmäler deutscher Tonkunst, además de haber editado, entre 1895 y 1901, las obras de Sweelinck, en doce volúmenes. Entre 1918 y 1926, junto con Johannes Wolf y Max Schneider (1875-1967), editó el formidable Archiv für Musikwissenschaft. Entre 1903 y 1914 había sido el editor jefe del Sammelbände der Internationalen Musikgesellschaft. La base de la gran obra de Seiffert está en su inmenso conocimiento de la música barroca en general y de la música holandesa y alemana para teclado en particular, que adquirió 
mediante un largo trabajo y la consiguiente familiaridad con una diversidad de fuentes. Sus ediciones de los autores del barroco y sus realizaciones de las partes de continuo son de un mérito relevante, así como su interés en la iconografía, que cultivó con todo entusiasmo y todo éxito.

Lange tuvo dos colaboradores que vale la pena mencionar, ya que se trata de especialistas excepcionales en América Latina y su actividad conjuntá está relacionada con ese marco intelectual y académico al que hemos estado haciendo referencia. Uno es Hans Joachim Köllreutter (1915), compositor, pedagogo y director de orquesta egresado de la Academia de Música de Berlín y alumno de Paul Hindemith (1805-1963) en composición y Hermann Scherchen (1891-1966) en dirección de orquesta, Gustav Scheck (1901) en flauta, Carl Adolf Martienssen (1881-1955) en piano y Schünemann y Seiffert en musicología. En 1937, Köllreutter se fue a vivir a Brasil, donde realizó toda una labor como maestro, musicólogo, director de orquesta y administrador de la cultura en su calidad de funcionario del Instituto Goethe. Luego vivió en Delhi (1965-1969) y en Tokio (1970-1975) como representante regional y director, respectivamente, de la misma institución cultural de Alemania. Sus obras creadoras sobresalientes son: Mutaçoes (1953) para orquesta, Sunyata (1968) para flauta, orquesta de cámara con instrumentos occidentales e hindúes y cinta, India Report (1967), con texto de Lutze, para soprano, narrador, coro de cámara, coro parlante y orquesta de cámara con instrumentos hindúes y europeos, Tanka I (1971) para narrador y koto, y Tanka II (1973) para narrador y piano. Con Köllreutter, Lange publicó una revista que, si bien no duró mucho tiempo, tuvo una muy bien definida importancia: Música viva, editada en 1940 y 1941 en Río de Janeiro.

El otro colaborador editorial importante de Lange fue Juan Bautista Plaza (1891-1965), compositor y musicólogo venezolano. Plaza hizo estudios en el muy sofisticado y especializado campo de la música religiosa de la iglesia católica y recibió el título de Maestro en Composición Sagrada de la Escuela Superior de Música Sacra de Roma en 1923. Allí estudió con dos de las grandes figuras de la especialidad: el sacerdote Raffaele Casimiri (1880-1943), erudito, ejecutante y profesor de canto gregoriano, y el monje Paolo Ferretti (1866-1938), experto en canto gregoriano también y director del Instituto Pontificio de Música Sacra, además de abad del monasterio de San Juan en Parma, una de las más grandes autoridades en música sacra del siglo $\mathrm{XX}$.

Lange se asoció con Plaza para producir la primera colección histórica organizada de música latinoamericana, el Archivo de música colonial venezolana, publicado en doce volúmenes en Montevideo, entre 1941 y 1943. 
Plaza fue también funcionario cultural de su país y logró muchas metas en el área pedagógica. Además fue organista, director del coro de la catedral de Caracas y de la Orquesta Sinfónica de Venezuela. Sus obras más notables, aparte de nueve misas y diversos motetes, salmos y ofertorios, son cinco piezas para orquesta: El picacho abrupto (1926), Vigilia (1928), Campanas de Pascua (1930), Fuga criolla (1931) y Fuga romántica venezolana (1950). Se trató de una mentalidad musical muy interesante, cuya sociedad con Lange produjo resultados de primera.

En una vida tan larga y fructífera como la de Lange, aparece siempre una miríada de personalidades cuya vida y obra entronca con la del personaje central, a veces tangencialmente, pero produciendo siempre resultados de interés e importancia en diversos estratos. La intención de estas líneas no es el retratar todo el prolongado y fértil periplo intelectual de Lange, sino exponer muy someramente su vinculación escolástica con una gran trayectoria tradicional de pensamiento musicológico. Tanto Plaza como Köllreutter han sido mencionados con esa idea e intención en mente, de un modo lateral, como colaboradores, que tienen, además, una vida intelectual propia y fecunda. Pero en su calidad de socios académicos de Lange, su aparición en este contexto se utiliza para ejemplificar un sistema de trabajo. El resultado inmediato del criterio referido es la omisión de muchísimos nombres de personajes asociados con la obra de Lange, así como el silencio acerca de muchas otras realizaciones editoriales, bibliográficas y organizacionales de Lange. Hay gente tan importante como Manuel Ponce (1882-1948), Juan Carlos Paz (1901-1972), Kurt Reinhard (19141979), Domingo Santa Cruz (1899-1987) y muchos otros, cuyas asociaciones musicales y científicas con Lange tuvieron resultados impresionantes. Pero tanto esas obras como esas colaboraciones deben quedar excluidas de un texto cuya finalidad es mentar los brillantes antecedentes académicos de Lange, pues dichas personas no fueron sus profesores.

Toda esta confluencia de mentes, vidas y obras, hasta en sus remotos antecedentes del siglo XIX, que llegaron a Lange mediante una tradición viva y continua, hizo síntesis con su vida y obra. Estos antecedentes universitarios, históricos, científicos y académicos, son importantes cuando atendemos a su trabajo como fundador de la Biblioteca Estatal de Grabaciones del SODRE, su introducción de los estudios musicológicos en el Instituto de Estudios Superiores de Unuguay, su fundación del Instituto Interamericano de Musicología de Montevideo (1933), proyección de su idea del "Americanismo musical", el establecimiento de su Boletín latinoamericano de música en 1995 y su idea de los Monumenta Musicae Brasilie, que resulta la proyección en esa esfera geográfica del Denkmäler deutscher 
Tonkunst de Seiffert. De su amplia labor pedagógica y sus notables resultados han hablado ya muchos con gran extensión y, en realidad, su carrera tiene tanta proyección y es tan conocida que resulta ocioso y limitado detallarla en estas líneas.

Las brillantes dotes de Lange y su infatigable labor dieron como resultado una obra que bien puede calificarse como extraordinaria en su campo y en su momento. Pero la tradición escolar de Lange, como base académica y erudita de su trabajo, tiene la bien marcada fisonomía del apoyo intelectual de robusta solidez y consagrada cepa en el cual Lange tuvo el tino y la suerte de fundamentar sus años de formación escolástica.

\section{BIBLIOGRAFÍA}

Besseler, H.: ed. Musik und Bild: Festschrift Max Seiffert, in Verbindung mit Fachgenossen, Freunden und Schülern, Kassel, 1938.

Blankenburg, W.: "Max Seiffert", Die Musikforschung, vol. II, 1949, p. 2

Bose, F.: "Sudamerikanische Musikforschung", Acta Musicologica, vol. XXIX, 1957, p. 43 .

Chase, G: "An Anniversary and a New Start", Yearbook, Inter-American Institute for Musical Research, vol. I, 1965, p. 1 .

"Francisco Curt Lange and 'Americanismo Musical", InterAmerican Monthly, vol. II/5, 1943, p. 33.

-_Linking the Americas", Musical America, vol. LIX/3, 1939, p" 224 .

Clercx-Lejeune, S y van den Liden, A.: eds. Hommage à Charles van den Borren à l'occasion du centenaire de sa naissance, Bruselas, 1974.

- A.: eds. Hommage à Charles van den Borren: mélanges, Amberes, 1945

A: "Les septante-cinq ans de Charles van den Borren", Revue belge de musicologie, vol. III, 1949, pp. 207-246.

- A.: eds. Liber amicorum Charles van den Borren, Amberes, 1964.

Glosson, E. "E. M. von Hornbostel et l'ethnographie musicale”, Guide musicale, vol. IX, 1914; p. 335.

Dean, W.: "The True Carmen?", The Musical Times, vol. CVI, 1965, p. 846

Dette, A: Nikisch, Leipzig, 1922.

Espinosa, G.: "Un explorador musical uruguayo", Américas, vol. I/2, 1949, p. 25.

Festschrift zum 50. Geburtstag Adolf Sandberger, München, 1918.

$\mathrm{G}_{.}$Reese y R. Brandel: eds. The Commonwealth of Music in Honor of Curt Sachs, Nueva York, 1965.

Geipel, I.: "Paul Mies 70 Jahre", Musikhandel, vol X, p. 303, Colonia, 1959.

Hahn, K: "Verzeichnis der wissenschaftlichen Arbeiten von Curt Sachs", Acta musicologica, vol. XXIX, 1957, p. 94 . 
Kahl, W.: "Ernst Bücken", Rheinische Musiker, vol. I, 1960, p. 31.

— "Ernst Bücken", Die Musikforschung, vol. III, 1950, p. 12.

Lemacher H. y Schmidt-Görg, J. (eds.) Studien zur Musikgeschichte des Rheinlandes." Festschrift zum 80. Geburtstag von Ludwig Schiedermair, Colonia, 1956.

"Musikhandschriften aus der Nachlass Ernst Bückens in der Universität-und Stadtbibliothek Köln", Aus der Welt der Bibliothekars, Colonia, 1961, p. 59.

Koellreutter, H. J.: History of Western Music, Nueva Delhi, 1970.

- Jazz Harmonia, Sao Paulo, 1969.

Lange, F.C.: "As dancas coletivas públicas no periodo colonial brasileiroe danca das corporacoes de oficios em Minas Gerais”, Barroco, vol I, 1969, p. 15.

"Colonial Music in Latin American Hands", Musical America, vol. LIX/14, 1939 , p. 8

—_ "Der Fall Domenico Zipoli: Verlauf und Stand einer Berichtigung", Musicae scientiae collectanea" Festschrift Karl Gustav Fellerer, 1973, p. 327.

- "Die Musik von Minas Gerais", Música, vol. XI, 1947, p. 375.

"Estudios brasileños (Mauricinas) I: manuscritos de la biblioteca nacional de Rio de Janeiro", Revista de Estudios Musicales, vol. I/3, 1950, p. 99.

- "La música en Minas Gerais, un informe preliminar", Boletín Latinoamericano de Música, vol. VI, 1946, p. 409.

"Vida y muerte de Louis Moreau Gottschalk en Río de Janeiro (1869): el ambiente musical en la mitad del segundo imperio", Revista de Estudios Musicales, vol, II/4, 1950-1951, p. 43, núms 5/6, p. 97.

"Villa-Lobos, un pedagogo creador", Boletin latino-americano de música, vol. I, 1935 , p. 189 ,

Lloyd, L. S.: "Hornbostel's Theory of Blown Fifths", Monthly Musical Record, vol, LXXVI, 1946, pp. 3, 35.

Mies, P.: "Über die Tonmalerei", resúmenes publicados en Zeitschrift für Ästhetik und allgemeine Kunstwissenschaft, vol. VII, pp. 397, 578, Bonn, 1912.

- Die geistlichen Kantaten Johann Sebastian Bachs und der Hörer von heute, Wiesbaden, 1959-1960

- Studien zum Klavierspiel Beethovens und seiner Zeitgenossen (coautor con $\mathrm{H}_{\text {. }}$ Grundmann), Bonn, 1966, vol. II, 1970.

— Johannes Brahms." Werke, Zeit, Mensch, Leipzig, 1930.

— Die Bedeutung der Skizzen Beethovens zur Erkenntnis seines Stiles, Leipzig, 1925.

-_ Skizzen aus Geschichte und Ästhetik der Musik, Golonia, 1926.

— Franz Schubert, Leipzig, 1954.

— Die Krise der Konzertkadenz bei Beethoven, Bonn, 1970.

Pérez, A.C.: "Discovery in Minas Gerais: on the Trail of 18th Century Musical Sources", Américas, vol XIII/1, 1961, p 24.

Pfhol, F : Artur Nikisch, Hamburgo, 2/1925.

Plaza, J. B.: "Música colonial venezolana", Letras Venezolanas, 1958, núm. 11.

— "Music in Caracas during the Colonial Period (1770-1811)", Musical Quarterly, vol. XXIX, 1943, p. 198. 
Preussner, E.: "Georg Schünemann", Die Musikforschung, vol. I, 1948, p. 19.

Reese, G. y Brandel, R., eds. The Commonwealth of Music in Honor of Curt Sachs, Nueva York, 1965.

Sachs, C.: "Erich M. von Hornsbostel zum 50. Geburtstag", Zeitschrift für Musikwissenschaft, vol. IX, 1926-1927, p. 308.

Sandberger, A.: Beiträge zur Geschichte der Bayerischen Hofkapelle unter Orlando di Lasso, Leipzig, 1894-1895.

- Sandberger, A: Emmanuel Chabriers Gwendoline, Munich, 1898.

—_ Über zwei ehedem Wolfgang Mozart zugeschriebene Messen, Munich, 1907.

Schiedermair, L: "Adolf Sandberger", Zeitschrift für Musikwissenschaft, vol. XVII, 1935 , p. 1.

- Bayreuther Festspiele im Zeitalter des Absolutismus, Leipzig, 1908.

- Die Briefe Mozarts und seiner Familie, Leipzig, 1914.

- Mozart: sein Leben und seine Werke, Munich, 1922, vol. II, 1948.

- Der junge Beethoven, Leipzig, 1925.

- Die deutsche Oper." Grundzüge ihres Werdens und Wesens, Leipzig, 1930. Musik am Rheinstrom, Colonia, 1947

Schmitz, A.: Beethoven und die Gegenwart. Ludwig Schiedermair zum 60. Geburtstag, Berlín, 1937.

Schneider, M.: "Max Seiffert zum. 9. Februar 1938", Archiv für Musikforschung, vol. III, 1938", p. 1.

Segnitz, E.: Artur Nikisch, Leipzig, 1920.

Urtubey, P. S : Las obras colectivas de Francisco Curt Lange, Buenos Aires, 1974

Van den Borren, C.: "Tobacco and Coffee in Music", Musical Quarterly, vol. XVIII, 1932, p. 355 .

Wellek, A.: "Die Aufspaltung der Tonhöhe in der Hornbostelschen Gehörpsychologie und die Konsonanztheorien von Hornbostel und Krüger", Zeitschrift für Musikwissenschaft, vol. XVI, 1934, pp. 481, 537. 